\title{
A STUDY TO ASSESS THE EFFECTIVENESS OF SLEEP HYGIENE ON QUALITY OF SLEEP AMONG INSOMNIAC PATIENT ADMITTED IN SMVMC AND HOSPITAL AT PUDUCHERRY
}

\author{
Mrs. Sivasankari* | Dr. Manjit Kaur Salwan** \\ *Ph.D. Scholar, Himalayan University, Itanagar, Arunachal Pradesh, India. \\ **Research Supervisor, Himalayan University, Itanagar, Arunachal Pradesh, India. \\ DOI: http://doi.org/10.47211/trr.2020.v06i01.015 \\ Received $24^{\text {th }}$ May 2020, Accepted $10^{\text {th }}$ June 2020, Available online $25^{\text {th }}$ June 2020.
}

ABSTRACT:

Insomnia is highly prevalent, has associated daytime consequences which impair job performance and quality of life, and is associated with increased risk of comorbidities including depression. These practice parameters provide recommendations regarding behavioural and psychological treatment approaches, which are often effective in primary and secondary insomnia. These recommendations replace or modify those published in the 1999 practice parameter paper produced by the American Sleep Disorders Association. Methods: A quantitative research approach was considered as appropriate for present study. The study was conducted in Sri Manakula Vinayagar Medical College and Hospital at Puducherry with 6 week of time duration. Totally 50 sample were selected through Purposive sampling technique, self-Structured Questionnaire used to gathered data. Descriptive and Inferential analytical methods like three dependent Paired t-test and Chi-square were used to find the effectiveness of Sleep hygiene. Result: Study finding shows that Pre-test mean value is 10.53 (32\%) and the standard deviation value is 6.42 , where as in post-test mean value is $30.18(73 \%)$ and Standard deviation value is 10. Mean value increased from 10.53 to 30.18 , " $t$ " value is 13.9 and $p$-value is 0.0005 which is statistically highly significant at the level of $p<0.001$. It shows that Quality of Sleep was increased among Insomniac patients after administering the Sleep Hygiene. Conclusion: The study revealed that there was increased quality of Sleep among Insomniac Patients after the administration of Sleep Hygiene especially in Patient with absent of Psychiatric Disorder and Symptoms than Physical Disorder and Patient who were in age group of $26-45$ years than other age group. Moreover educated patients were shows more effectiveness than other groups. The study findings were statistically significant at $P<0.001$; this level of significance revealed that $\mathrm{H}_{1} \mathrm{H}_{2}$, was supported in this present study.

Key Words: - Insomnia, sleep Hygiene, Quality of sleep and Insomniac patient.

\section{ABOUT AUTHORS:}

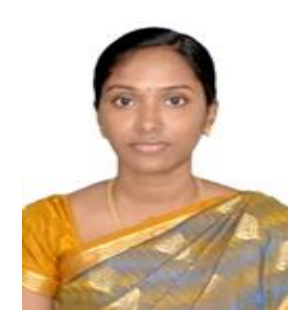

Author Mrs. Sivasankari is Ph.D. Scholar at Himalayan University, Itanagar, Arunachal Pradesh, India. She has published papers in various National and International Journals.

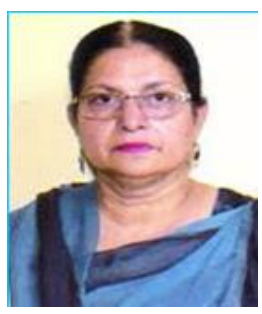

Author Dr. Manjit Kaur Salwan is an active researcher with many publications in his name. She has attended and organized various National and International conferences and has given extensive lectures. 


\section{INTRODUCTION:}

Sleep hygiene (SH) refers to a list of behaviours, environmental conditions, and other sleep-related factors that can be adjusted as a stand-alone treatment or component of multimodal treatment for patients with insomnia. Insomnia is highly prevalent, has associated daytime consequences which impair job performance and quality of life, and is associated with increased risk of comorbidities including depression. These practice parameters provide recommendations regarding behavioural and psychological treatment approaches, which are often effective in primary and secondary insomnia. These recommendations replace or modify those published in the 1999 practice parameter paper produced by the American Sleep Disorders Association.

\section{STATEMENT OF THE PROBLEM:}

A Study to Assess the Effectiveness of Sleep Hygiene on quality of sleep among Insomnia patient admitted in SMVMC Hospital at Puducherry.

\section{OBJECTIVES:}

$>$ To assess the Quality Sleep among Insomniac Patient.

$>$ To assess the effectiveness of Sleep Hygiene on Quality of Sleep among Insomniac Patient.

$>$ To associate the Effectiveness of Sleep Hygiene on Quality of Sleep among Insomniac Patient with their selected demographic variables.

\section{HYPOTHESIS:}

$>$ H1: There will be a significant different in the Quality of Sleep Insomniac patient before and after administering Sleep Hygiene.

$>$ H2: There will be a significant association between the Effectiveness of Sleep Hygiene on Quality of Sleep among Insomniac Patient with their selected demographic variables.

\section{METHODOLOGY:}

\section{RESEARCH APPROACH:}

- A quantitative research approach was selected for this study to determine the effectiveness of Sleep RESEARCH DESIGN: Hygiene on Quality of Sleep among Insomniac patient.

- Pre Experimental - one group pre-test-post-test design was selected this study. POPULATION:

- The population selected for this study includes all Insomniac Patient.

SAMPLE:

- Insomniac Patient who admitted in SMVMC Hospital at Puducherry and Patient who met the SAMPLE SIZE: inclusion criteria of the study.

- The sample size of the study consists of 50 Insomniac Patient.

\section{SAMPLING TECHNIQUE:}

- The 50 Patient were selected by using Purposive Sampling Method. STUDY VARIABLES:

- Independent variable: Sleep Hygiene is the independent variable.

- Dependent variable: Quality of Sleep is the dependent variable.

\section{SETTINGS OF THE STUDY:}

Sri Manakula Vinayagar Medical College and Hospital at puducherry was selected and conducted this study, situated at a distance of $2 \mathrm{~km}$ from Sri Manakula Vinayagar Nursing College.

\section{CRITERIA FOR SAMPLE SELECTION:}

INCLUSION CRITERIA:

- Both male and female Patient.

- Patient Who were willing to participate

EXCLUSION CRITERIA:

- Patients who are suffering with Other type of Sleeping Disorders

- Patient who were undergoing other Psychotherapy.

DEVELOPMENT AND DESCRIPTION OF DATA COLLECTION TOOL:

In this study Research Instrument in two sections

- Section I: Demographic Variables.

- Section II: Quality of Sleep. 


\section{ARTICLES}

SECTION I: The demographic data contains Age of the Patient, Sex, Level of Insomnia, Marital History, Religion, Residence, Education, Occupation, Family Income, and Family History of Mental Illness.

SECTION II: Assessment of Quality of Sleep.

The structured Questionnaire was developed by Researcher was used as research instrument for this study after an extensive review of literature and expert's opinion to assess the quality of sleep of Insomniac Patient. It consists 60 items and each item carry 1 mark, the scores between 1-20 shows as mild Insomnia, and scores between 21 -30 indicate as moderate Insomnia, 31-60 resembles as Sever Insomnia.

\section{DISCUSSION:}

The goal of the study was to evaluate the effectiveness of Sleep Hygiene on Quality of Sleep among Insomniac Patients. A total number of 50 Patient were selected through Purposive sampling technique who were fulfilled the study inclusion criteria. Informed Consent was obtained from the study samples. The quality of Sleep was assessed by using self-Structured Questionnaire instrument. Study finding shows that Pre-test mean value is 10.53 (32\%) and the standard deviation value is 6.42 , where as in post-test mean value is 30.18 ( $73 \%$ ) and Standard deviation value is 10 . Mean value increased from 10.53 to 30.18 , " $t$ " value is 13.9 and $p$-value is 0.0005 which is statistically highly significant at the level of $p<0.001$. It shows that Quality of Sleep was increased among Insomniac patients after administering the Sleep Hygiene.

\section{CONCLUSION:}

The study revealed that there was increased quality of Sleep among Insomniac Patients after the administration of Sleep Hygiene especially in Patient with absent of Psychiatric Disorder and Symptoms than Physical Disorder and Patient who were in age group of 26 - 45 years than other age group. Moreover educated patients were shows more effectiveness than other groups. The study findings were statistically significant at $\mathrm{P}<0.001$; this level of significance revealed that $\mathrm{H}_{1}, \mathrm{H}_{2}$, was supported in this present study.

\section{RECOMMENDATIONS:}

Based on findings of the present study, the following recommendations have been made,

- Similar study can be conducted in other parts of the state of country with a large sample.

- The same study can be conducted in different settings.

- The same study can be conducted with Research design.

- The same study can be conducted with control group.

- The same study can be conducted as comparative study with other Psychotherapy like time out, Modelling, shaping, Meditation, Token Economy, Thought Stopping. 


\section{ARTIC LES}

\section{REFERENCE:}

1. James Benjamin Concise, Textbook of Child \& Adolescents Psychiatry. 10th Edition. Philadelphia: Lipponcott Williams \& Wilkins Publications; 2009, page No: 338-450.

2. Van Hulle.V.Carol, Developmental Structure of Genetic Influences on Mental Retardation across Childhood and Adolescence. J Abnor Psychol publication. 2009

3. Clifford T Morgan, Introduction to Psychology. 7th Edition. New Delhi: TATA Mc Graw Hill; 2003.

4. Catherine D, Sleep Hygiene Practices in a Population-Based Sample of Insomniacs, International journal of abnormal psychology, Volume 28, Issue 5, May 2014, Pages 611-615.

5. Edward, et al, Use of sleep hygiene in the treatment of insomnia, Author links open overlay panel, Volume 7, Issue 3, June 2013, Pages 215-225.

6. Thomas, Practice Parameters for the Psychological and Behavioural Treatment of Insomnia: An Update, An American Academy of Sleep Medicine Report, Volume 29, Issue 11, November 2010, Pages 1415-1419,

7. Imargaret. D, Sleep Hygiene and Melatonin Treatment for Children and Adolescents With ADHD and Initial Insomnia, Author links open overlay panel, Volume 45, Issue 5, May 2015, Pages 512-519

8. Barron' A. et al, Offenders with intellectual disability: the size of the problem and therapeutic outcomes, Article first published online: Journal of Intellectual Disability Research Volume 46, Issue 6, pages 454-463, September 2008.

9. Cross, John G. The Token Economy Reinforcement Theory and the Consumer Model, Journal of Instructional Psychology;March2010, Vol. 37 Issue 1, p49.

10. http://www.childlineindia.org.in

11. http://www.medline.com

12. http://www.pubmed.com 